\title{
Bone Resorption in Post-menopausal Women with Normal and Low BMD Assessed with Biochemical Markers Specific for Telopeptide Derived Degradation Products of Collagen Type I
}

\author{
J.-Y. Reginster, ${ }^{1,2}$ Y. Henrotin, ${ }^{2}$ C. Christiansen, ${ }^{3}$ E. Gamwell-Henriksen, ${ }^{4}$ O. Bruyere, ${ }^{2}$ J. Collette, ${ }^{2}$ S. Christgau ${ }^{4}$ \\ ${ }^{1}$ WHO Collaborating Center for Public Health Aspects of Osteoarticular Disorders \\ ${ }^{2}$ Bone and Cartilage Metabolism Unit, University of Liège, Liège, Belgium \\ ${ }^{3}$ Center for Clinical and Basic Research, Ballerup, Denmark \\ ${ }^{4}$ Osteometer Bio Tech A/S, Herlev, Denmark
}

Received: 22 November 2000 / Accepted: 1 May 2001 / Online publication: 8 August 2001

\begin{abstract}
Biochemical markers of bone resorption can be used clinically to predict the risk of osteoporosis-related fractures (prognostic tool) and to assess the response of an osteoporotic patient to an antiresorptive therapy (monitoring tool). Our aim was to assess the ability of four currently marketed biochemical markers of bone resorption, based on the measurement of degradation products from collage type I telopeptides to monitor the elevated resorption associated with menopause. Women (846) were stratified for menopause, age, and bone mineral density and the following markers were measured: urinary cross-linked Ntelopeptides of type I collagen (NTx), the levels of breakdown products of type I collagen C-telopeptides in serum (S-CTx), and in urine, by ELISA (U-CTx-E), and RIA (UCTx-R). Furthermore, the ratio $(\alpha / \beta)$ between the $\alpha \mathrm{L}$ form of CTx measured in the CTx RIA and the $\beta \mathrm{L}$ form measured in the ELISA was calculated. The mean difference was calculated for each marker in women with osteopenia (Op) or osteoporosis (PMO) (WHO definition) compared with healthy premenopausal (Pre) women and postmenopausal (N Post) women with normal bone mass. Serum CTx showed the highest elevation in post- compared with premenopausal women. All marker values were significantly higher in Op and PMO subjects compared with both Pre and to $\mathrm{N}$ Post women. Compared with premenopausal values, the largest elevation in both Op and PMO women was observed for serum CTx. Compared with N Post, urine NTx showed the highest increase in OP subjects. The $\alpha / \beta$ CTx ratio was elevated in post- compared with Pre women, but there was no difference in the ratio among $\mathrm{N}$ Post, Op, or PMO women. In conclusion, postmenopausal women showed elevated turnover with all bone resorption markers, but with substantial individual variation in resorption levels. Furthermore, the turnover process in postmenopausal women appears to be quantitatively different from the premenopausal stage, apparent as altered $\alpha / \beta$ CTx ratios.
\end{abstract}

Correspondence to: J.-Y. Reginster
Key words: Osteoporosis - Biochemical markers - Bone turnover - Collagen type I - Antiresorptive therapies Diagnosis.

Assessment of bone physiology has been greatly improved by the development of specific and sensitive markers of bone remodeling $[1,2]$. Biochemical markers have advantages because they are noninvasive, inexpensive, reflect turnover in the whole skeleton, and allow repeated evaluation $[3,4]$. Furthermore, biochemical markers of bone remodeling are a valuable supplement to bone mineral density measurement (BMD), as they provide a dynamic measure of the current bone turnover state compared with the static measure of skeletal status provided by BMD. Thus, biochemical markers of bone turnover provide a rapid assessment of the effects of antiresorptive therapies such as hormone replacement therapy, bisphosphonates, and calcitonin which induce a decrease in the levels of bone markers that is correlated with the long-term effect of such treatments on bone mass [5-15]. Due to the small annual changes in $\mathrm{BMD}$, the effect of antiresorptive therapy can only be reliably monitored by BMD measurement after several years followup [5, 10, 13].

Bone markers might also be used to prognose a high rate of bone less in postmenopausal women who would subsequently develop osteoporosis and fractures [16-25]. Bone turnover increases after menopause and remains elevated in late postmenopausal women. It has been demonstrated that bone resorption markers are an independent predictor of fracture risk with the same predictive value as BMD measurements $[19,22]$.

In recent years, new sensitive and specific markers of 
bone resorption have been developed. These assays measure degradation products derived from the N- and C- terminal telopeptide regions of type I collagen in either urine or serum samples [1, 5, 25-31]. The application of these markers in daily practice will depend upon their ability to rank healthy subjects regarding their turnover status and to distinguish between individual subjects in terms of their response to antiresorptive therapy [1, 4, 32]. For monitoring use, the intraindividual variation increase seen at menopause and responsiveness to various anti-resorptive therapies is important [5, 27, 33]. For prognosis of future BMD and fracture risk, marker levels and their changes in the individual patient must be correlated with levels and changes in BMD and ultimately with fracture occurrence.

Clinical information may also be derived from biochemical marker data is an assessment of the average 'age' of the resorbed bone. $\beta$-Aspartate isomerization, which occurs as a slow spontaneous reaction in the C-telopeptide of type I collagen, has been suggested to provide a measure of the bone 'age' [34, 35]. C-telopeptide fragments measured in the urine CrossLaps (CTx) radioimmunoassay (RIA) are in the authentic $\alpha \mathrm{L}$ form characteristic of newly synthesized collagen molecules [34, 36]. The corresponding fragments measured in the urine CTx ELISA, as well as in the serum CTx assay, are in the isomerized $\beta \mathrm{L}$ form, and thus these molecules are 'older' than the molecules measured in the RIA [35]. By calculating a ratio between the measures obtained in the two assays (RIA/ELISA $\approx \alpha / \beta$ ), the age of the resorbed bone can be measured. In addition to isomerization, the aspartate residue of the CTx epitope is also susceptible to racemization, and laboratory assays specific for the racemized forms have been developed [35]. Ratios between the $\alpha \mathrm{L}$ form and the racemized forms also provides a measure of collagen age, and such ratios are elevated in Pagets disease and certain forms of bone metastasis [35, 37]. However, whether these ratios have any value for clinical assessment of osteoporosis remains to be demonstrated.

To address these issues, we have measured four currently marketed biochemical markers of bone turnover in a cohort of 846 women, stratified for menopause, age, and BMD. We calculated the mean changes for each parameter in women with Op or PMO (WHO definition) [38] compared with healthy Pre and N Post women with normal bone mass.

\section{Material and Methods}

\section{Experimental Subjects}

The patients were recruited from two outpatients facilities (Center for Clinical and Basic Research, Ballerup, Denmark and Bone and Cartilage Metabolism Unit, University of Liège, Liège, Belgium) specializing in diagnosis and treatment of skeletal disorders. The study population (846 women) were spontaneously measured for bone mineral density and bone turnover. Women suffering from disorders or treated with drugs that might interfere with bone den- sity and/or bone turnover were excluded from the study. The women were stratified based on their menopausal status (premenopausal versus postmenopausal), and BMD values. BMD values were classified in accordance with the WHO definition of normality $(\mathrm{N}$ Post)(T-score at the spine and hip >-1), Op (T-score at the spine between -1 and -2.5 ), and PMO (T-score at the spine <-2.5) [38]. Blood samples were taken after overnight fasting. Venous blood (10-15 ml) was drawn from the fasting women between 9:00 a.m. and 11:00 a.m. The blood sample was centrifuged, divided into two to three aliquots, and stored at $-80^{\circ} \mathrm{C}$ until assayed. Second morning spot urine was concomitantly collected and stored under similar conditions. The height and weight of the subjects were determined and used to calculate BMI (body mass index). Menopausal age was noted for the postmenopausal women.

\section{Measurement of Biochemical Markers}

Serum breakdown products of type I collagen C-telopeptides (CTx) were measured with an enzyme-linked immunosorbent assay (ELISA) (Serum CrossLaps ${ }^{\mathrm{TM}}$ One Step ELISA; Osteometer BioTech A/S, Herlev, Denmark) using two monoclonal antibodies directed against a $\beta$-isomerized form of an 8 amino acid sequence (EKAHD- $\beta$-GGR) of the C-telopeptide of the $\alpha 1$ chain of type I collagen [30]. To obtain a signal in the assay, two sequences must be cross-linked. The assay has intra- and interassay CVs of 5.2 and $6.7 \%$, respectively, and results are expressed in $\mathrm{pM}$.

Urinary CTx were simultaneously measured both by ELISA and RIA (CrossLaps ${ }^{\mathrm{TM}}$ ELISA and $\alpha$-CrossLaps ${ }^{\mathrm{TM}}$; Osteometer BioTech A/S, Herlev, Denmark) The assays have intra- and interassay CVs of 5.4 and $7.0 \%$, respectively for the ELISA and 8.6 and $9.8 \%$ for the RIA assay. The ELISA uses polyclonal antibodies directed against the $\beta$-isomerized sequence (EKAHD- $\beta$-GGR) and is based on the competitive binding of antibodies to either soluble peptide or to immobilized synthetic peptide [8,31]. The RIA uses a monoclonal antibody (MAb) raised to the 8 amino acid sequence (EKAHDGGR) and is based on the competitive binding of ${ }^{125} \mathrm{I}$ labeled Mab to either soluble peptide or to immobilized synthetic peptide [36]. Urinary cross-linked N-telopeptides of type I collagen (NTx) were measured with an ELISA (Osteomark®) Ostex International, Inc., Seattle, WA, USA) using a Mab directed against the N-telopeptide-to-helix intermolecular cross-linking domain of the type I collagen isolated from human urine [26]. The ELISA is based on the competitive binding of the Mab to either urinary or immobilized antigen. The results were expressed in nanomoles bone collagen equivalents per liter (nM BCE) and were corrected by the creatinine concentration $(\mathrm{mM})$ to be expressed in $\mathrm{nM} \mathrm{BCE} / \mathrm{mmol}$. The assay has intra- and interassay CVs of 6.0 and $4.0 \%$, respectively.

The urine creatinine level was measured by photometric determination with the Jaffe method [39] on the multitest analyzer system Merck MEGA® (Merck, Darmstadt, Germany). Each biochemical measurement was performed in duplicate on fresh thawed urine or serum aliquot and repeated when the CV for the double determination was above $15 \%$.

\section{Standardization of Urinary CrossLaps Assays}

The $\mu \mathrm{g} /$ liter values obtained in the CrossLaps RIA and ELISA assays is not corrected to the actual concentration of peptide, but standardized to a master calibrator used since the CrossLaps ELISA was first developed. In order to obtain values in the correct $\mu \mathrm{g} / \mathrm{liter}$ units, a correction factor of $3.45^{*} 10^{-2}$ for the ELISA and $1.93^{*} 10^{-2}$ for the RIA assay has to be used [40]. For further conversion to molar concentration, a molecular weight of 869 $\mathrm{g} / \mathrm{mol}$ for the CrossLaps epitope should be used. The $\alpha / \beta$ CTx ratio has to be multiplied by 0.56 to get the ratio in actual molar terms between the two forms of the collagen type I C-telopeptide in urine. However, the concentrations obtained directly in the assay have been used throughout, as this allows direct comparisons with other published reports on the CrossLaps assays. 
Table 1. Biomarker levels in the study cohort stratified according to menopausal status.

\begin{tabular}{|c|c|c|c|c|c|c|c|}
\hline Premenopausal & $\mathrm{n}$ & $\frac{\text { Age }}{29}$ & $\frac{\mathrm{s}-\mathrm{CTx}}{29}$ & $\frac{\mathrm{u}-\mathrm{CTx} \mathrm{E}}{27}$ & $\frac{\mathrm{u}-\mathrm{CTx}-\mathrm{R}}{25}$ & $\frac{\mathrm{u}-\mathrm{NTx}}{28}$ & $\frac{\alpha / \beta \text { CTx }}{25}$ \\
\hline & Average & 38.42 & 1838.90 & 198.40 & 229.21 & 42.64 & 1.16 \\
\hline \multirow[t]{3}{*}{ Postmenopausal } & $\mathrm{n}$ & 817 & 800 & 796 & 778 & 798 & 778 \\
\hline & Average & 69.79 & 3753.72 & 243.83 & 340.5 & 58.92 & 1.52 \\
\hline & SD & 8.43 & 2095.69 & 154.83 & 340.5 & 58.92 & 1.52 \\
\hline
\end{tabular}

The values listed for the urinary CrossLaps assays are the values obtained in the assays. For conversion to actual concentrations, a correction factor of $3.45 * 10^{-2}$ for the ELISA and $1.93 * 10^{-2}$ for the RIA assay has to be used [40]. Likewise, the $\alpha / \beta$ CTx ratio has to be multiplied with 0.56 to get the actual ratio between the non-isomerized $\alpha$ form and the isomerized $\beta$ form of the collagen type I C-telopeptide fragments in urine measured in the CrossLaps assays

\section{Analysis of Database}

The results of the four biochemical markers of bone resorption were analyzed with the Excel 5.0 software. For each category of patients and for each biochemical parameter, results are provided as the mean and standard deviation. A regression analysis was used to calculate the Pearson's coefficient for the correlation between each of the markers of bone resorption in the whole population. The significance of differences between groups was calculated by nonparametric Mann-Whitney testing. For the Op and PMO women, the results (after correction of urinary measurements for creatinine) are also expressed as the increase in the mean compared with Pre and N Post women. A similar calculation is provided for N Post versus Pre women. We then calculated the percentage of Op or PMO women whose measured values of each of the bone markers (corrected for urinary creatinine) was higher than the mean $+2 \mathrm{SD}$ of the value measured, for the same marker, in Pre or N Post women. Multiple regression analysis was used to adjust for the influence of age when assessing the significance of the observed difference in markers between the groups for the two markers showing a significant correlation to age (s-CTx and uNTx).

\section{Results}

Table 1 shows the mean value and SD for the four biochemical markers of bone resorption, for Pre and $\mathrm{N}$ Post women. The ratio between CTx measured by RIA $(\alpha \mathrm{L})$ and ELISA $(\beta L)$ has also been calculated and included in Table 1. All biochemical markers, as well as the $\alpha / \beta$ CTx ratio, were significantly elevated in the postmenopausal group. The difference between the two groups was most pronounced for the serum CTx marker (s-CTx, 99.8\% increase in postmenopausal women compared with premenopausal). Average BMI among the pre- and postmenopausal women was $23.24 \pm 2.78$ and $25.29 \pm 3.54$, respectively. This significant difference $(P=0.013)$ was the result of a significant difference in heights $(167.63 \pm 5.21$ versus $162.57 \pm$ $5.48 \mathrm{~cm}$ ) between the two groups whereas weight was similar in pre- and postmenopausal women (65.37 \pm 8.94 versus $66.76 \pm 9.29 \mathrm{~kg})$.

Table 2 shows the Pearson's coefficient for the correlations between the markers. Correlation between the marker levels and age of the sampled individuals, as well as the $\alpha / \beta$ CTx ratio, is also given in Table 2 . The correlations between the resorption markers are highly significant $(P<0.001)$ : the highest correlation is observed in the two methods used to assess urinary CTx, both before and after correcting for urinary excretion for creatinine $(r=0.832$ and $r=0.770$, respectively). The markers also show a correlation to the age of the sampled individuals, ranging from weak correlation for the two urinary CTx assays $(P=0.05$ and $P=$ 0.016 for the ELISA and RIA assay, respectively) to a stronger correlation for the serum CTx and urinary NTx assays $(P<0.001)$. The CTx markers show a relatively low but significant $(P<0.001)$ correlation to the $\alpha / \beta$ CTx ratio. The u-CTx ELISA measuring the $\beta \mathrm{L}$ form and the serum CTx assay, which is also specific for the $\beta \mathrm{L}$ forms of the CTx molecules, show an inverse correlation to the $\alpha / \beta$ ratio.

The postmenopausal women described in Table 1 were further divided according to spine BMD measurements into osteoporotic (PMO, s-BMD < premenopausal mean -2.5 $\mathrm{SD}$ ), osteopenic (Op, s-BMD between -2.5 and -1 SD below premenopausal mean), and normal postmenopausal (N Post, with s-BMD above premenopausal mean -1SD) (Table 3). All marker values are elevated in Op and PMO subjects compared with both Pre and N Post women (Table 3). The significance of the differences was calculated by Mann-Whitney testing. Serum CTx and urinary NTx values were adjusted for the influence of age by multiple regression analysis. Compared with premenopausal values, the largest increase in both Op and PMO women is observed for the mean serum CTx (Fig. 1). Serum CTx measured significantly elevated levels in the $\mathrm{N}$ Post group compared with premenopausal women. The levels of the urinary resorption markers were not significantly elevated in the group of postmenopausal women with normal BMD compared with premenopausal women (Table 3 ). The $\alpha / \beta$ CTx ratio was significantly higher in $\mathrm{N}$ Post, Op, and PMO women compared with the premenopausal women, but Op and PMO women did not have significantly different $\alpha / \beta$ ratios compared with $\mathrm{N}$ Post women. BMI in the three cohorts was not significantly different $(25.77 \pm 2.98,24.84 \pm 2.71$, and $25.33 \pm 5.35 \mathrm{~kg} / \mathrm{m}^{2}$, respectively, for the $\mathrm{N}$ Post, Op, and PMO groups). The menopausal age was also similar in all 
Table 2. Correlation between biochemical markers. Urinary marker values were corrected for creatinine for correlation to serum CTx, age, and $\alpha / \beta$ CTx ratio. Values represent Pearson's correlation coefficients

\begin{tabular}{|c|c|c|c|c|c|}
\hline & NTx & sCTx & uCTx-E & uCTx-R & $\alpha / \beta$ CTx \\
\hline SCTx & $0.432^{* * * *}$ & & $0.572^{* * * *}$ & 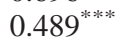 & $-0.129^{\text {**** }}$ \\
\hline UCTxR & $0.696^{* * * *}$ & 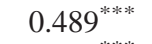 & $0.832^{* * * *}$ & & 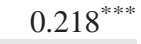 \\
\hline$\alpha / \beta$ CTx & -0.019 & $-0.129^{* * *}$ & $-0.247^{\text {**** }}$ & $0.218^{\text {**** }}$ & \\
\hline Age & $0.124^{\text {**** }}$ & $0.169^{* * * *}$ & $0.068^{*}$ & $0.085^{*}$ & 0.026 \\
\hline
\end{tabular}

*** $P<0.001 ; * P<0.05$

Table 3. Number of subjects (n), mean value (mean) and standard deviation (SD), and median for each resorption marker in the postmenopausal women stratified in three groups according to BMD

\begin{tabular}{|c|c|c|c|c|c|c|c|c|}
\hline Group & $\mathrm{n}$ & & Age & s-CTx & u-CTx E & u-CTx-R & $\mathrm{u}-\mathrm{NTx}$ & $\alpha / \beta$ CTx \\
\hline BMD & 104 & $\mathrm{SD}$ & 6.5 & 1833.2 & 123.7 & 213.7 & 37.3 & 1.07 \\
\hline Osteopenia & & Average & 68.9 & 3742.6 & 240.6 & 349.3 & 56.0 & 1.56 \\
\hline \multirow[t]{2}{*}{$(\mathrm{Op})$} & 359 & $\mathrm{SD}$ & 8.6 & 2041.4 & 151.0 & 308.3 & 73.9 & 1.07 \\
\hline & & Difference to Pre & $P<0.0001$ & $P<0.0001^{*}$ & $P=0.032$ & $P=0.0003$ & $P=0.027 *$ & $P<0.0001$ \\
\hline \multirow[t]{3}{*}{$(\mathrm{PMO})$} & 338 & SD & 8.8 & 2184.2 & 162.3 & 250.0 & 47.0 & 0.7 \\
\hline & & Difference to Pre & $P<0.0001$ & $P<0.0001^{*}$ & $P=0.0018$ & $P<0.0001$ & $P<0.0001 *$ & $P<0.0001$ \\
\hline & & Difference to $\mathrm{N}$ Post & $P<0.0001$ & $P=0.0009^{*}$ & $P<0.0001$ & $P<0.0001$ & $P=0.006^{*}$ & $\mathrm{NS}(\mathrm{p}>0.1)$ \\
\hline
\end{tabular}

${ }^{*}$ Serum CTx and urinary NTx values were corrected for the influence of age by regression analysis for calculation of the significance levels of the difference between the groups

three groups $(48.69 \pm 6.70,49.64 \pm 6.43$, and $49.27 \pm 4.36$ years, respectively, for the N Post, Op, and PMO groups).

The percentage of Op or PMO women with values higher than premenopausal mean $+2 \mathrm{SD}$ was calculated for each of the four markers (Fig. 1B). The mean urinary concentration of CTx and NTx was increased 32 and 58\%, respectively, in Op and PMO when compared with $\mathrm{N}$ Post, and the mean serum CTx concentration was 19 and 32\% elevated in these two groups, respectively (Fig. 2). The percentage of Op and PMO women with values higher than the mean value $+2 \mathrm{SD}$ observed in normal postmenopausal women is in the same range for all markers, the values observed for urinary CTx measured by ELISA being slightly higher than those observed for the other markers (Fig. 2B).

\section{Discussion}

CTx and NTx are widely considered the most sensitive and specific of the currently marketed markers of bone resorption $[1,25,27]$. These markers have been extensively used for both the assessment of therapeutic efficacy of antiresorptive drugs in osteoporosis and for prediction of fracture risk in postmenopausal women [6-24]. We measured urinary and serum CTx and urinary NTx in a large cohort of untreated, healthy women stratified on the basis of their menopausal status and BMD.

Urinary CTx was measured in both ELISA and RIA formats. These two assays employ different antibodies: the RIA assay is specific for the authentic $\alpha \mathrm{L}$ form of the CTx epitope, whereas the antibody employed in the ELISA is specific for the isomerized ('aged') $\beta \mathrm{L}$ form [34]. Thus it is possible to calculate the ratio between the $\alpha \mathrm{L}$ and the $\beta \mathrm{L}$ form of CTx, and this ratio has been suggested to provide an estimate of the 'age' of the resorbed bone [34, 35].

All markers of bone resorption were significantly correlated, with the highest correlation coefficient being observed for urinary CTx, assessed by ELISA and RIA, followed by the correlation between urinary NTx and urinary CTx ELISA. These results are in accordance with previous studies reporting correlation coefficients slightly lower or in the same range as those observed in the present investigation $[16,17,21,22,30]$. Interestingly, the $\alpha / \beta$ CTx ratio showed relatively poor correlations with the individual bone resorption markers. This suggests that this ratio provides a qualitatively different measure of the turnover process. The higher $\alpha / \beta$ ratio in the postmenopausal women is likely to be a reflection of increased turnover rate, and thus a decreasing 'age' of the resorbed collagen molecules [35, 37].

All four markers were significantly elevated in the postmenopausal compared with premenopausal women, in 


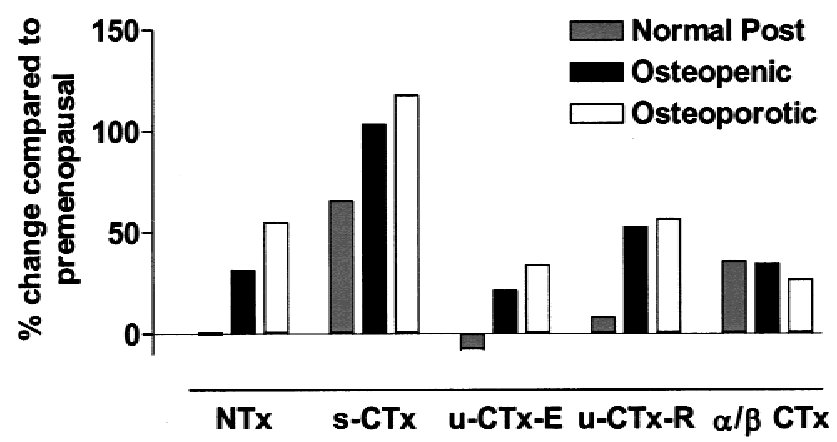

B

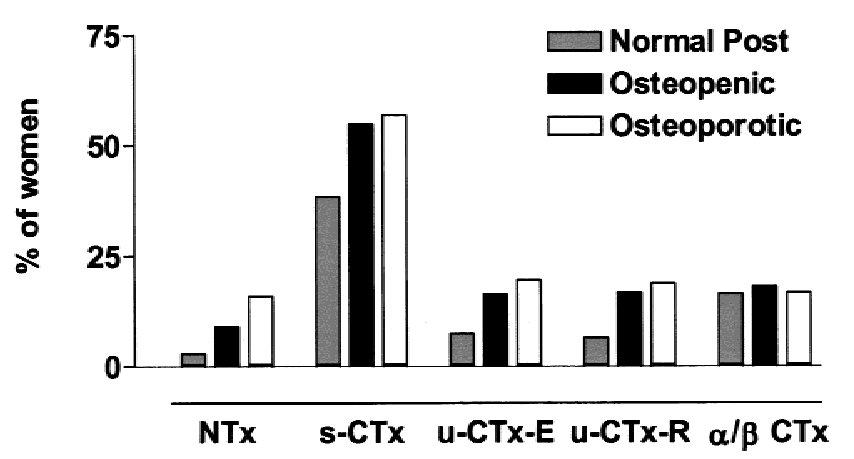

Fig. 1. (A) Increase (\%) in the biochemical markers mean values among postmenopausal women with normal BMD, osteopenic, or osteoporotic women compared with values of premenopausal women. (B) Percentage of the osteopenic and osteoporotic women with values of each of the biochemical markers higher than the mean +2 SD for the premenopausal women.

agreement with results reported in previous studies [17, 30, 31, 41-46]. However, the differences between the pre- and postmenopausal women were relatively low for the three urinary markers, ranging from a 23 to a $49 \%$ increase (for urine CTx ELISA and urine CTx RIA, respectively).

When the postmenopausal women were divided into three groups according to BMD status (osteporotic, osteopenic, and normal), only the osteoporotic and osteopenic women had a significant elevation in the levels of urinary resorption markers compared with the pre- and postmenopausal women with normal BMD. The serum CTx marker showed a significant elevation of $64 \%$ in the N Post group compared with the premenopausal group and increases of 103.5 and $117.9 \%$ in the Op and PMO groups. The lack of a significant elevation in urinary markers of bone resorption found in the group of postmenopausal women with normal BMD may be considered to be in disagreement with many previous reports $[17,30,31,41]$, but more in accordance
J.-Y. Reginster et al.: Bone Resorption Markers in Postmenopausal Women

A

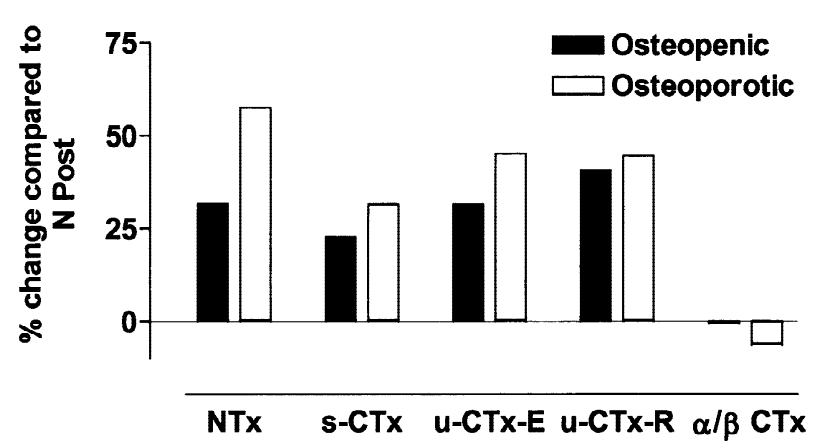

B

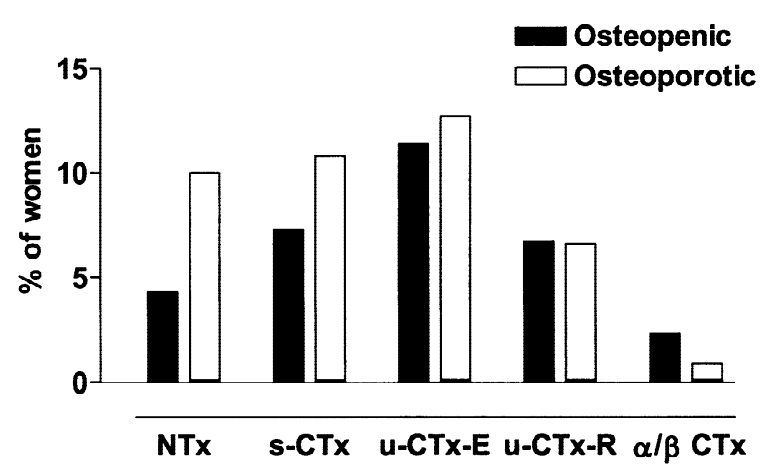

Fig. 2. (A) Increase (\%) in the biochemical marker mean values from osteopenic or osteoporotic women compared with values of normal postmenopausal women. (B) Percentage of the osteopenic and osteoporotic women with values of each of the biochemical markers higher than the mean $+2 \mathrm{SD}$ for the normal postmenopausal women.

with other studies, which have either failed to show such differences $[25,43]$ or reported a relatively large scatter of the resorption markers around the mean values [42, 44-46]. Most of these studies defined "healthy" postmenopausal women on the absence of clinical osteoporosis, without assessment of BMD. In the present work, "normal" postmenopausal women (N Post) were selected on the basis of BMD at the spine and hip levels above premenopausal mean -1 $\mathrm{SD}$ (T-score -1). If a high rate of bone turnover is effectively correlated to a fast rate of bone loss, both immediately after the menopause and later in life [16, 17, 21, 22], it might thus be logical that $\mathrm{N}$ Post women with the highest BMD have only a relatively placid increase in bone turnover compared with Prewomen. This hypothesis, however, does not explain the significantly elevated levels of serum CTx seen among the N Post women. Serum and urine samples were obtained at the same time, from the same patients, and processed under similar conditions. Thus, the samples should be directly comparable, and technical issues are un- 
likely to affect the discrepancy. Urine samples were corrected for creatinine, excluding a possible role of renal dysfunction, at any rate, very unlikely in women between 55 and 65 years old. We have no definite explanation for the discrepancy between serum and urinary CTx. However, this discrepancy may support the suggestion that serum CTx measurements can be superior to urinary tests, in terms of specificity and sensitivity, for the detection of hyper remodeling stages $[5,27,29,33]$.

The urinary $\alpha / \beta$ CTx ratio was significantly elevated in all three cohorts of postmenopausal women compared with the premenopausal group. However, the $\alpha / \beta$ CTx ratio was similar in normal, osteopenic, and osteoporotic postmenopausal women, suggesting that decreased half-life of bone collagen reflected in the elevated $\alpha / \beta$ CTx ratio is a common feature occurring in the menopause, when the turnover rate is increased $[34,35,37]$. When the $\alpha / \beta$ CTx ratio was corrected to reflect the actual molar ratios of the two forms, the ratio in pre- and postmenopausal women was 0.65 and 0.85 , respectively. This is in accordance with previously published data [40].

Very weak correlations were seen between urinary CTx and age, whereas the correlation between serum CTx and age as well as urine NTX and age was significant. It may be considered surprising that no significant correlation was found between $\alpha / \beta$ CTx ratio and age. However, it has been shown that collagen type I isomerization/racemization have reached equilibrium in adult individuals $[34,35]$. After 2030 years the $\alpha / \beta$ CTx ratio remains relatively constant and reflects the age of the resorbed collagen rather than the age of the individual. Menopause induces an increased remodeling state reflected as an increase in the $\alpha / \beta$ CTx ratio, and the elevated $\alpha / \beta$ CTx levels occurring at menopause persist in older women.

Our results showing a consistent increase in urinary and serum markers of bone resorption in osteopenic and osteoporotic women compared with premenopausal or normal postmenopausal women is in accordance with previous findings. Women with low BMD and/or fractures of the spine, forearm, or hip were repeatedly characterized by a high level of bone resorption, apparent as increased values of serum and urinary $\mathrm{C}$ - and $\mathrm{N}$ - terminal telopeptides fragments derived from type 1 collagen [11, 33, 43, 47-50]. Serum CTx shows the highest discrimination between premenopausal women and all groups (normal, osteopenic, and osteoporotic) of postmenopausal women whereas urinary NTx was the assay showing the highest differentiation between postmenopausal women with normal BMD and Op and PMO women. The value of biochemical markers of bone resorption as predictors of further occurrence of fractures is based on the hypothesis that women with the highest rate of bone turnover will experience faster loss of bone and will develop subsequent fractures. This was confirmed by prospective studies showing that markers of resorption could predict the risk of hip fractures independently of
BMD $[18,22]$. In this perspective, the optimal marker would be the one offering the best discrimination between osteoporotic subjects and age-matched normal subjects. All the investigated markers appropriately discriminate between postmenopausal women with normal BMD and osteopenic or osteoporotic subjects. Urinary NTX shows the most pronounced increase (57.6\%) in osteoporotic women compared with the normal BMD group. When considering the percentage of osteopenic or osteoporotic women with values higher than the mean $+2 \mathrm{SD}$ of the normal postmenopausal women, 11.4 and $12.7 \%$ of the women, respectively, had significant elevation of urinary CTx ELISA levels. The other markers identified a lower portion of the osteopenic and osteoporotic women as high turnover individuals by this stratification method. The $\alpha / \beta$ CTx ratio was almost identical in the three cohorts of postmenopausal women suggesting that this parameter reflects a different physiological process than the individual resorption markers [35, 40].

We conclude that all the four collagen type I-derived markers of bone resorption are significantly increased in osteopenic or osteoporotic subjects compared with normal postmenopausal women. The ratio between authentic and 'aged' CTx molecules ( $\alpha / \beta$ ratio) appeared to provide a quantitatively different measure of the bone turnover process. The clinical application of such a ratio will have to be assessed in future studies.

\section{References}

1. Watts NB (1999) Clinical utility of biochemical markers of bone remodelling. Clin Chem 45:1359-1368

2. Christenson RH (1997) Biochemical markers of bone metabolism: an overview. Clin Biochem 30:573-593

3. Eastell R, Blumshohn A (1997) The value of biochemical markers of bone turnover in osteoporosis. J Rheum 24:12151217

4. Lindsay R (1999) Clinical utility of biochemical markers. Osteoporosis Int 2:S29-S32

5. Christgau S, Bitsch-Jensen O, Hannover Bjarnasson N, Gamwell Henriksen E, Qvist P, Alexandersen P, Bang Henriksen D (2000) Serum CrossLaps for monitoring the response in individuals undergoing antiresorptive therapy. Bone 26:505-511

6. Hesley RP, Shepard KA, Jenkins DK, Riggs BL (1998) Monitoring estrogen replacement therapy and identifying rapid bone losers with an immunoassay for deoxypyridinoline. Osteoporosis Int 8:159-164

7. Chen JT, Hosoda K, Hasumi K, Ogata E, Shiraki M (1996) Serum N-terminal osteocalcin is a good indicator for estimating responders to hormone replacement therapy in postmenopausal women. J Bone Miner Res 11:1784-1792

8. Bonde M, Qvist P, Fledelius C, Riis B, Christiansen C (1995) Applications of an enzyme immunoassay for a new marker of bone resorption (CrossLaps): follow-up on hormone replacement therapy and osteoporosis risk assessment. J Clin Endocrinol Metab 80:864-868

9. Riggs BL, Melton LJ, O'Fallon W (1996) Drug therapy for vertebral fractures in osteoporosis: evidence that decreases in bone turnover and increases in bone mass both determine anti-fracture efficacy. Bone 18:197-201

10. Greenspan SL, Parker RA, Ferguson L, Rosen HN, MaitlandRamsey L, Karpf DB (1998) Early changes in biochemical markers of bone turnover predict the long-term response to 
alendronate therapy in representative elderly women: a randomised clinical trial. J Bone Miner Res 13:1431-1438

11. Seibel MJ, Cosman F, Shen V, Gordon S, Dempster DW, Ratcliffe A, Lindsay R (1993) Urinary hydroxypyridinium crosslinks of collagen as markers of bone resorption and estrogen efficacy in postmenopausal osteoporosis. J Bone Miner Res 8:881-889

12. Rosen CJ, Chesnut CH, Mallinak NJ (1997) The predictive value of biochemical markers of bone turnover for bone mineral density in early postmenopausal women treated with hormone replacement or calcium supplementation. J Clin Endocrind Metab 82:1904-1910

13. Chesnut CH, Bell HH, Clark GS, Drinkwater BL, English SC, Johnson CC, Notelovitz M, Rosen C, Cain DF, Flessland KA, Mallinak NJ (1997) Hormone replacement therapy in postmenopausal women: urinary N-telopeptide of type I collagen monitors therapeutic effect and predicts response of bone mineral density. Am J Med 102:29-37

14. Riis BJ, Overgaard K, Christiansen C (1995) Biochemical markers of bone turnover to monitor the bone response to postmenopausal hormone replacement therapy. Osteoporosis Int 5:276-280

15. Overgaard K, Christiansen C (1996) A new biochemical marker of bone resorption for follow-up on treatment with nasal salmon calcitonin. Calcif Tissue Int 59:12-16

16. Ross PD, Knowlton W (1998) Rapid bone loss is associated with increased levels of biochemical markers. J Bone Miner Res 13:297-302

17. Garnero P, Sornay-Rendu E, Chapuy MC, Delmas PD (1996) Increased bone turnover in late postmenopausal women is a major determinant of osteoporosis. J Bone Miner Res. 11:337-349

18. Van Daelle PLA, Seibel MJ, Burger H, Hofman A, Grobee DE, Van Leeuwen JP, Birkenhager JC, Pols HA (1996) Casecontrol analysis of bone resorption markers, disability and hip fracture risk: the Rotterdam study. Br Med J 312:1045

19. Ravn P, Rix M, Andreassen H, Clemmensen B, Bidstrup M, Gunnes M (1997) High bone turnover is associated with low bone mass and spinal fracture in postmenopausal women. Calcif Tissue Int 60:255-260

20. Melton LJ, Khosla S, Atkinson EJ, O'Fallon WM, Riggs BL (1997) Relationship of bone turnover to bone density and fractures. J Bone Miner Res 12:1083-1091

21. Keen RW, Nguyen T, Sobnack R, Perry LA, Thompson PW, Spector TD (1996) Can biochemical markers predict bone loss at the hip and spine? A 4-year prospective study of 141 early postmenopausal women. Osteoporosis Int 6:399-406

22. Garnero P, Hausnerr E, Chapuy MC, Marcelli C, Grandjean H, Muller C, Cormier C, Breart G, Meunier PJ, Delmas PD (1996) Markers of bone resorption predict hip fracture in elderly women: the EPIDOS prospective study. J Bone Miner Res 11:1531-1538

23. Garnero P, Dargent-Molina P, Hans D, Schott AM, Breart G, Meunier PJ, Delmas PD (1998) Do markers of bone resorption add to bone mineral density and ultrasonographic heel measurement for the prediction of hip fracture in elderly women? The EPIDOS prospective study. Osteoporosis Int 8:563-569

24. Schneider DL, Barrett-Connor EL (1997) Urinary Ntelopeptide levels discriminate normal, osteopenic, and osteoporotic bone mineral density. Arch Intern Med 157:12411245

25. Woitge HW, Pecherstorfer M, Li Y, Keck AV, Horn E, Ziegler R, Seibel MJ (1999) Novel serum markers of bone resorption: clinical assessment and comparison with established urinary indices. J Bone Miner Res 14:792-801

26. Hanson DA, Weis MA, Bollen AM, Maslan SL, Singer FR, Eyre DR (1992) A specific immunoassay for monitoring human bone resorption: quantitation of type I collagen crosslinked N-telopeptides in urine. J Bone Miner Res 7:12511258

27. Rosen HN, Moses AC, Garber J, Iloputaife ID, Ross DS, Lee SL, Greenspan SL (2000) Serum CTx: a new marker of bone resorption that shows treatment effect more often than other markers because of low coefficient of variability and large changes with bisphosphonate therapy. Calcif Tissue Int 66:100-103

28. Clemmens JD, Herrick MW, Singer FR, Eyre DR (1997) Evidence that serum NTx (collagen type I N-telopeptides) can act as an immunochemical marker of bone resorption. Clin Chem 43:2058-2063

29. Christgau S, Rosenquist $\mathrm{C}$, Alexandersen $\mathrm{P}$, Bjarnason $\mathrm{NH}$, Ravn P, Fledelius C, Herling C, Qvist P, Christiansen C (1998) Clinical evaluation of the serum CrossLaps one step ELISA, a new assay measuring the serum concentration of bone-derived degradation products of type I collagen Ctelopeptides. Clin Chem 44:2290-2300

30. Rosenquist C, Fledelius C, Christgau S, Pedersen BJ, Bonde M, Qvist P, Christiansen C (1998) The serum CrossLaps one step ELISA. The first quantitative determination in serum of degradation products from C-terminal telopeptides of type I collagen from bone using monoclonal antibodies. Clin Chem 44:2293-2301

31. Bonde M, Qvist P, Fledelius C, Riis BJ, Christiansen C (1994) Immunoassay for quantifying type I collagen degradation products in urine evaluated. Clin Chem 40:2022-2025

32. Blumsohn A, Eastell R (1997) The performance and utility of biochemical markers of bone turnover: Do we know enough to use them in clinical practice? Ann Clin Biochem 34:449-459

33. Christgau S, Bjarnason NH, Rigault MY, Pedersen BJ, Littau M, Heelsberg M, Rosenquist C (1998) Intra-individual variation and response to antiresorptive therapy assessed by bone resorption measurements with the serum CrossLaps one step ELISA. Ligand Assay 3:200-205

34. Fledelius C, Johnsen AH, Cloos P, Bonde M, Qvist P (1997) Characterization of urinary degradation products derived from type I collagen. J Biol Chem 272:9755-9763

35. Cloos P, Fledelius C (2000) Collagen fragments in urine derived from bone resorption are highly racemized and isomerized: a biological clock of protein ageing with clinical potential. Biochem J 345:473-480

36. Fledelius C, Kolding I, Qvist P, Bonde M, Hassager C, Reginster JY, Hejgaard J, Frookiaer H, Christiansen C (1997) Development of a monoclonal antibody to urinary degradation products from the C-terminal telopeptide $\alpha 1$ chain of type I collagen. Application in an enzyme immunoassay and comparison to CrossLaps ELISA. Scand J Clin Lab Invest 57:7383

37. Gineyts E, Cloos P, Borel O, Grimaud L, Delmas PD, Garnero P (2000) Racemization and isomerization of type I collagen C-telopeptides in human bone and soft tissue: assessment of tissue turnover. Biochem J 345:481-485

38. WHO Technical Report Series (1994) Assessment of fracture risk and its application to screening for postmenopausal osteoporosis. Geneva, n ${ }^{\circ} 843$, ISBN 9241208430

39. Jaffe M (1886) Ueber den niederschlag, welchen pricrinsaure in normalen harn erzeugt und eine neue reaction des kreatinins. Hoppe Seylers Z Phys Chem 10:391-400

40. Garnero P, Fledelius C, Gineyts E, Serre C-M, Vignot E, Delmas PD (1997) Decreased $\beta$-isomerization of the Cterminal telopeptide of type I collagen $\alpha 1$ chain in Pagets disease of bone. J Bone Miner Res 12:1407-1415

41. Kelly PJ, Pocock NA, Sambrook PN, Eisman JA (1989) Age and menopause-related changes in indices of bone turnover. $\mathrm{J}$ Clin Endocrinol Metab 69:1160-1165

42. Riis BJ (1993) Biochemical markers of bone turnover II: diagnosis, prophylaxis, and treatment of osteoporosis. Am J Med 95:17-21

43. Del Campo MT, Gonzalez-Casaus ML, Aguado P, Bernard M, Carrera F, Martinez ME (1999) Effects of age, menopause and osteoporosis on free, peptide-bound and total pyridinium crosslink excretion. Osteoporosis Int 9:449-454

44. Fledelius C, Riis BJ, Overgaard K, Christiansen C (1994) The diagnostic validity of urinary-free pyridinolines to identify women at risk of osteoporosis. Calcif Tissue Int 54:381-384

45. Hassager C, Risteli J, Risteli L, Christiansen C (1994) Effect 
of the menopause and hormone replacement therapy on the carboxy-terminal pyridinoline cross-linked telopeptide of type I collagen. Osteoporosis Int 4:349-352

46. Garnero P, Gineyts E, Riou JP, Delmas PD (1994) Assessment of bone resorption with a new marker of collagen degradation in patients with metabolic bone disease. J Clin Endocrinol Metab 79:780-785

47. McLaren AM, Hordon LD, Bord HA, Robins SP (1992) Urinary excretion of pyridinium crosslinks of collagen in patients with osteoporosis and the effects of bone fracture. Ann Rheum Dis 51:648-651

48. Hoshimo H, Takahashi M, Kushida K, Ohishi T, Inoue T
(1998) Urinary excretion of type I collagen degradation products in healthy women and osteoporotic patients with vertebral and hip fractures. Calcif Tissue Int 62:36-39

49. Eastell R, Robins SP, Colwell T, Assiri AMA, Riggs BL, Russell RGG (1993) Evaluation of bone turnover in type I osteoporosis using biochemical markers specific for both bone formation and bone resorption. Osteoporosis Int 3:255-260

50. Earnshaw SA, Cawte SA, Worley A, Hosking DJ (1998) Colles' fracture of the wrist as an indicator of underlying osteoporosis in postmenopausal women: a prospective study of bone mineral density and bone turnover rate. Osteoporosis Int $8: 53-60$ 